Canadian

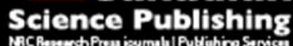

Applied Physiology, Nutrition, and Metabolism Physiologie appliquée, nutrition et métabolisme

\title{
Predicting peak oxygen uptake from submaximal exercise after spinal cord injury
}

\begin{tabular}{|r|l|}
\hline Journal: & Applied Physiology, Nutrition, and Metabolism \\
\hline Manuscript ID & apnm-2015-0670.R1 \\
\hline Manuscript Type: & Article \\
\hline Date Submitted by the Author: & $14-$-Feb-2016 \\
\hline Complete List of Authors: & $\begin{array}{l}\text { Totosy de Zepetnek, Julia; McMaster University, Department of Kinesiology } \\
\text { Au, Jason; McMaster University, Department of Kinesiology } \\
\text { Hol, Adrienne; University of British Columbia, Department of Physical } \\
\text { Therapy; GF Strong Rehabilitation Research Center, Rehabilitation } \\
\text { Research Program } \\
\text { Eng, Janice; University of British Columbia, Department of Physical } \\
\text { Therapy; GF Strong Rehabilitation Research Center, Rehabilitation } \\
\text { Research Program } \\
\text { MacDonald, Maureen; McMaster University, Department of Kinesiology }\end{array}$ \\
\hline Keyword: & $\begin{array}{l}\text { Arm Ergometry, Peak Oxygen Consumption, Prediction Equation, } \\
\text { Submaximal Exercise Test, spinal cord injury < nervous system }\end{array}$ \\
\hline
\end{tabular}




\section{Predicting peak oxygen uptake from submaximal exercise after spinal cord injury}

Julia O. Totosy de Zepetnek ${ }^{1}$, Jason S. Au ${ }^{1}$, Adrienne L. Hol ${ }^{2,3}$, Janice J. Eng ${ }^{2,3}$, Maureen J. MacDonald $^{1}$

${ }^{1}$ Department of Kinesiology, McMaster University, Hamilton, ON, Canada L8S 4L8

${ }^{2}$ Department of Physical Therapy, University of British Columbia, Vancouver, BC, Canada V6T 1Z3

${ }^{3}$ Rehabilitation Research Program, GF Strong Rehab Centre, Vancouver Coastal Health, Canada V5Z 2G9

\section{Corresponding Author:}

Maureen J. MacDonald

McMaster University, Department of Kinesiology

1280 Main Street West, Hamilton, ON L8S 4L8

Phone: 905-525-9140 ext. 23580;

Fax: 905-523-6011

Email:<macdonmj@mcmaster.ca $>$ 


\section{Abstract:}

Purpose: To determine the validity of the six-minute arm ergometry test (6MAT) in predicting peak oxygen consumption $\left(\mathrm{VO}_{2}\right.$ peak) in individuals with chronic spinal cord injury (SCI).

Methods: Fifty-two individuals with chronic SCI (age 38 \pm 10 years; American Spinal Injury Association Impairment Scale A-D, neurological level of injury C1-L2, years post-injury $13 \pm 10$ years) completed an incremental arm ergometry $\mathrm{VO}_{2}$ peak test and a submaximal 6MAT. Oxygen consumption data from both tests were used to create a predictive equation with regression analysis. Subsequently, a cross-validation group of an additional ten individuals with SCI (age 39 \pm 13 years; AIS A-D, NLI C3-L3, YPI 9 \pm 9 years) were used to determine the predictive power of the equation.

Results: All participants were able to complete both the $\mathrm{VO}_{2}$ peak and 6MAT assessments. Regression analysis yielded the following equation to predict $\mathrm{VO}_{2}$ peak from end-stage 6MAT $\mathrm{VO}_{2}: \mathrm{VO}_{2}$ peak $\left(\mathrm{mL} \cdot \mathrm{kg}^{-1} \cdot \mathrm{min}^{-1}\right)=1.501\left(6 \mathrm{MAT} \mathrm{VO}_{2}\right)-0.940$. Correlation between measured and predicted $\mathrm{VO}_{2}$ peak was excellent $(\mathrm{r}=0.89)$. No significant difference was found between measured $\left(17.41 \pm 7.44 \mathrm{~mL} \cdot \mathrm{kg}^{-1} \cdot \mathrm{min}^{-1}\right)$ and predicted $\left(17.42 \pm 6.61 \mathrm{~mL} \cdot \mathrm{kg}^{-1} \cdot \mathrm{min}^{-1}\right) \mathrm{VO}_{2}$ peak $(p=0.97)$. When cross-validated with a sample of ten individuals with SCI, correlation between measured and predicted $\mathrm{VO}_{2}$ peak remained high $(\mathrm{r}=0.89)$, with no differences between measured $\left(18.81 \pm 8.35 \mathrm{~mL} \cdot \mathrm{kg}^{-1} \cdot \mathrm{min}^{-1}\right)$ and predicted $\left(18.73 \pm 7.27 \mathrm{~mL} \cdot \mathrm{kg}^{-1} \cdot \mathrm{min}^{-1}\right) \mathrm{VO}_{2}$ peak $(\mathrm{p}=0.75)$.

Conclusions: Results suggest that $6 \mathrm{MAT} \mathrm{VO}_{2}$ can be used to predict $\mathrm{VO}_{2}$ peak among individuals with chronic SCI. The 6MAT should be used as a clinical tool for assessing aerobic capacity when peak exercise testing is not feasible.

Key Words: Arm Ergometry; Peak Oxygen Consumption; Prediction Equation, Submaximal Exercise Test, Spinal Cord Injury 


\section{Introduction:}

Individuals who have sustained a spinal cord injury (SCI) are at an increased risk of cardiovascular disease, the leading cause of mortality in chronic SCI (Myers et al. 2007). Aerobic capacity is an indirect measure of cardiovascular disease risk (Kohl 2001), and it has been suggested that low aerobic fitness increases the risk for cardiovascular disease after SCI (Cowan et al. 2010; de Groot et al. 2013; Hoffman 1986). Further, low aerobic fitness is associated with the inability to perform activities of daily living, increased frequency of urinary tract infections, and lower life satisfaction among individuals with SCI (Hjeltnes et al. 1990; van Koppenhagen et al. 2014). Conversely, peak aerobic capacity $\left(\mathrm{VO}_{2}\right.$ peak) is considered to be an excellent measure of both fitness and overall health in the able-bodied population (Aspenes et al. 2011), and is associated with functional ability after SCI (Dallmeijer et al. 2001).

$\mathrm{VO}_{2}$ peak among individuals with SCI is typically determined via an incremental arm-cycle ergometry test to volitional exhaustion. However, due to disruptions to the autonomic nervous system, upper body contractures, upper body injuries, and/or peripheral arm fatigue during testing, peak aerobic fitness tests can be unsafe or difficult to perform in many individuals with SCI (Goosey-Tolfrey 2006). Further, previous literature has shown a discrepancy between perceptual and physiological responses to exercise at high or peak levels of exertion in persons with SCI, suggesting typical physiological criteria used for peak oxygen consumption in the able-bodied population should be used with caution (Lewis et al. 2007). In an effort to improve the feasibility of cardiovascular fitness assessments in the SCI population, laboratory (Kofsky et al. 1983) and field-based (Franklin et al. 1990) submaximal exercise tests have been developed to address the challenges of peak exercise testing. However, issues remain with both of these existing submaximal tests as the laboratory-based study did not generate a prediction equation 
for estimating $\mathrm{VO}_{2}$ peak (Kofsky et al. 1983), and field submaximal tests introduce considerable variation in wheelchair propulsion distance at a given $\mathrm{VO}_{2}$ peak (Franklin et al. 1990). Further, these submaximal tests were developed using study designs that primarily included individuals with paraplegia, likely due to blunted heart rate response to exercise typically experienced among individuals with injuries $>$ T6. More recent studies have utilized peripheral rate of perceived exertion (RPE) as a means of estimating $\mathrm{VO}_{2}$ peak (Al-Rahamneh et al. 2011; GooseyTolfrey et al. 2014), as RPE has demonstrated a linear relationship with $\mathrm{VO}_{2}$ during arm cranking (Borg et al. 1987; Eston et al. 1986). While these studies cautiously concluded that RPE might be used to predict $\mathrm{VO}_{2}$ peak, no prediction equations were provided and both studies had small sample sizes and were conducted using populations of high-level athletes with relatively high upper-limb function (Al-Rahamneh et al. 2011; Goosey-Tolfrey et al. 2014). Previous research has demonstrated that, in the able-bodied population, active individuals show less variability in reproducing a given exercise intensity at a prescribed RPE compared to sedentary participants (Faulkner et al. 2007). These findings highlight the need to include a large heterogeneous sample in terms of fitness and injury characteristics when developing a $\mathrm{VO}_{2}$ peak prediction equation targeted for use in the general SCI population.

In 2007, Hol et al. developed the six-minute arm test (6MAT) as a submaximal exercise test with a fixed upper-limb power output for individuals with SCI (Hol et al. 2007). In this test, power output selection is based on lesion level, sex, wheelchair mobility (manual versus motorized), and activity level (physically inactive, active, or competitive). The 6MAT showed good reliably and validity (Hol et al. 2007), but the published study lacked appropriate power to create or validate a prediction equation to estimate $\mathrm{VO}_{2}$ peak in a generalized population of individuals with SCI. The purpose of the present study is to extend the findings of Hol et al. 
(2007) and develop and cross-validate a multiple regression equation for predicting $\mathrm{VO}_{2}$ peak in individuals with SCI.

\section{Methods:}

\section{Participants}

The data for this study were obtained from one existing data set from the original 2007 study $(n=27)$ (Hol et al. 2007), and further data collection $(n=25)$ to increase the total sample size to $\mathrm{n}=52$ for the development of a $\mathrm{VO}_{2}$ peak prediction equation. Data from ten additional individuals was used as a cross-validation group to validate the predictive equation. Inclusion criteria consisted of individuals: (a) who had sustained a traumatic SCI at least 1 year ago, (b) aged 18 to 65 at the time of assessment, and (c) who used a manual or power wheelchair for daily mobility. Research ethics committees at the University of British Columbia, Vancouver Coastal Health, and in Hamilton, Ontario approved study procedures. All of the participants gave written informed consent.

\section{Experimental Design}

Each participant came to one of the laboratory locations on two occasions. The first visit consisted of an incremental arm $\mathrm{VO}_{2}$ peak test to volitional exhaustion. The second visit took place 2-7 days following the first visit, and consisted of performance of the submaximal 6MAT exercise bout. Participants abstained from caffeine and alcohol for $\geq 12$ hours and physical activity for $\geq 24$ hours prior to both visits. Testing procedures from the Hol et al. study have been described previously (Hol et al. 2007), and were replicated as close as possible in the current data collection. However, different instrumentation was used for some of the physiological 
monitoring. In the current data collection, heart rate was monitored continuously by a 3-lead ECG (PowerLab 15T, ADInstruments) and a Polar heart rate monitor (Polar T31, Polar Electro Inc, Quebec, Canada). Blood pressure was assessed prior to, immediately following, and throughout recovery (Dinamap, GE Healthcare; Horten, Norway) to ensure that it returned to baseline values following the exercise tests.

Results from the $\mathrm{VO}_{2}$ peak and 6MAT exercise tests were used to create a prediction equation with regression analysis, which was then applied to the cross-validation group.

\section{Experimental Procedures}

\section{Peak Oxygen Uptake (VO $\mathrm{O}_{2}$ peak)}

Participants performed a symptom-limited graded cycle ergometer test on an electronically braked wall-mounted Lode arm ergometer (Lode B.V., Zernikepark 16, Groningen, the Netherlands). The midpoint of the ergometer was set at shoulder level and the distance was set to allow a slight flexion in the elbow when the arm was extended. Participants were asked to empty their bladder prior to the $\mathrm{VO}_{2}$ peak test to minimize the potential for episodes of autonomic dysreflexia.

Participants were asked to rest for two minutes during which baseline measurements of heart rate, blood pressure, expired gas (oxygen consumption $\left[\mathrm{VO}_{2}\right]$, carbon dioxide output $\left[\mathrm{VCO}_{2}\right]$ ), and ventilatory parameters (ventilation $\left[\mathrm{V}_{\mathrm{E}}\right]$, respiratory exchange ratio $[\mathrm{RER}]$ ) were assessed using a metabolic cart (Moxus Metabolic System, AEI Technologies Inc., Pittsburgh, PA). Participants with insufficient handgrip had their hands secured to the arm handles with tensor bandages. The incremental arm ergometer test began with no resistance at a cadence of 6080rpm. After a 1-minute warm-up, the resistance increased every minute by $5 \mathrm{~W}$ for participants with tetraplegia and $10 \mathrm{~W}$ for participants with paraplegia (Hol et al. 2007). Participants 
continued cycling until: (a) volitional fatigue, (b) they were unable to maintain a cadence of 30rpm, or (c) they exhibited any symptoms requiring immediate cessation of the test according to ACSM guidelines (ACSM 2013). Expired gas and ventilatory parameters were acquired throughout the protocol, and participants rated their RPE on the Borg CR10 scale immediately following the test. The highest 30 -second average of $\mathrm{VO}_{2}$ during the test was recorded as $\mathrm{VO}_{2}$ peak.

\section{Minute Arm Test (6MAT)}

Participants performed a single six-minute submaximal exercise bout on a mechanically braked Monark arm ergometer (Monark Rehab Trainer 881E; Monark Exercise AB, Varberg, Sweden). The Monark arm ergometer was chosen as it is commonly found in rehabilitation settings. The height was adjusted so that the shoulder joint was aligned with the crank axis of the ergometer. An individual power output was selected for each participant based on lesion level, sex, wheelchair mobility (manual versus motorized), and activity level (physically inactive, active, or competitive) according to clinical guidelines (Hol et al. 2007). Power output was set to elicit a heart rate of $60 \%$ to $70 \%$ of age-predicted heart rate peak for participants with low-level paraplegia, and a rating of 2 to 5 on the Borg CR10 RPE scale for participants with high-level paraplegia or tetraplegia.

Resting heart rate, blood pressure, expired gas, and ventilatory parameters were collected for two minutes prior to exercise. Participants were instructed to maintain a cycling rate of 60 $\mathrm{rev} \cdot \mathrm{min}^{-1}$ for the duration of exercise (actual power output was calculated based on $60 \mathrm{rev} \cdot \mathrm{min}^{-}$ ${ }^{1}$ ). Participants rated their RPE immediately following the test. A 30-second average of end stage oxygen consumption was recorded as the submaximal $\mathrm{VO}_{2}$ value for the $6 \mathrm{MAT}$. 


\section{Statistics}

Results from the submaximal and maximal exercise tests were used to create a predictive equation with multiple regression analyses. In order to avoid artificial inflation of the multiple correlation coefficient, it is recommended that there should be at least 20-40 participants for every predictor variable used in the model. With a sample size of $n=52$, we restricted our analysis to a maximum of two predictor variables in the $\mathrm{VO}_{2}$ peak prediction model (Heyward 2006). Blockwise entry was used to determine which variables best predicted $\mathrm{VO}_{2}$ peak, with 6MAT $\mathrm{VO}_{2}$ being the first predictor entered in each model. The following demographic variables were tested in the second block: age, years post-injury (YPI), American Spinal Injury Association Impairment Scale (AIS), body mass index (BMI), mean arterial pressure (MAP), and RPE.

Independence of errors was checked with the Durbin-Watson test, and homoscedasticity was tested by plotting the standardized residuals and predicted values. Normal distribution of regression residuals was tested using the Kolmogorov-Smirnov test. Standard error of estimate (SEE) was used to assess dispersion about the regression line and was calculated as follows:

$$
S E E=\sqrt{\frac{\sum\left(Y^{\prime}-Y\right)^{2}}{N}}
$$

where $\mathrm{Y}^{\prime}=$ estimated $\mathrm{VO}_{2}$ peak, $\mathrm{Y}=$ measured $\mathrm{VO}_{2}$ peak and $\mathrm{N}=$ sample size. Previous recommendations for SEE indicate a limit of $<5 \mathrm{~mL} \cdot \mathrm{kg}^{-1} \cdot \mathrm{min}^{-1}$ for able-bodied predictive submaximal tests (Heyward 2006). Paired-sample t-tests were performed to compare the predicted and measured $\mathrm{VO}_{2}$ peak.

Ten additional individuals with SCI (5 tetraplegia and 5 paraplegia) were used for a cross validation sample. In this subset, $6 \mathrm{MAT}$ and $\mathrm{VO}_{2}$ peak tests were performed as described above, 
and subsequently used to determine the predictive power of the equation. SEE was calculated to determine individual variability in comparison to the line representing the predictive equation. The correlation between $\mathrm{VO}_{2}$ peak predicted using the equation and measured $\mathrm{VO}_{2}$ peak in the cross validation sample was the cross-validation $r$. Paired-sample t-tests were performed to compare the predicted and measured $\mathrm{VO}_{2}$ peak. The level of significance was set at $\alpha<0.05$ for all tests. All statistical analyses were performed using SPSS for Mac (Version 20.0.0, Chicago, IL, USA).

\section{Results:}

All participants completed both the $6 \mathrm{MAT}$ and $\mathrm{VO}_{2}$ peak tests. Demographic and impairment characteristics for the validation and cross-validation groups can be found in Table 1. No significant differences were found in demographic or injury characteristics between groups. Of the 52 individuals in the validation group, there were 31 with tetraplegia and 21 with paraplegia. Of the ten individuals in the cross-validation group, there were 5 with tetraplegia and 5 with paraplegia. The distribution of lesion levels in the validation group is presented in Figure 1.

\section{$\mathrm{VO}_{2}$ peak and 6MAT}

Physiologic values obtained during the $\mathrm{VO}_{2}$ peak and 6MAT tests can be found in Table 2 and 3, respectively. No significant differences were found between the validation and crossvalidation groups for any exercise outcome.

During both the $\mathrm{VO}_{2}$ peak and 6MAT, 22 participants had their hands secured to the handles of the arm ergometer with tensor bandages. During $\mathrm{VO}_{2}$ peak testing, five participants experienced muscle spasms that briefly interrupted their cycling cadence. One participant stopped the test due to shoulder pain, and another stopped due to self-reported overheating. In 
both cases the $\mathrm{VO}_{2}$ peak test was repeated on a separate day after symptoms had improved. Average RER at the end of the $\mathrm{VO}_{2}$ peak test was $1.05 \pm 0.13$, indicating that participants reached close to their physiological peak during the test, and average RPE was $7.6 \pm 2.2$, indicating the participants were subjectively working at a 'very heavy' intensity.

During 6MAT testing, seven participants experienced muscle spams that briefly interrupted their cycling cadence. Appropriate power output targets for the 6MAT were difficult to determine in some cases. If the initial power output selection was too high (i.e. generated a heart rate $>70 \%$ of age-predicted peak or RPE $>5$ ) or too low (i.e. generated a heart rate $<60 \%$ of agepredicted peak or RPE <2), participants were given a 15-minute rest period (or until heart rate and $\mathrm{VO}_{2}$ returned to resting values) before a second attempt at an adjusted power output. Thirteen participants $(25 \%)$ repeated the 6MAT to obtain appropriate physiological or subjective exertion.

\section{Development of Prediction Equation}

All assumptions of regression were met. As a single predictor, 6MAT $\mathrm{VO}_{2}$ significantly predicted $\mathrm{VO}_{2}$ peak $(\mathrm{F}(1,50)=232.316 ; \mathrm{p}<0.01)$. Additionally, we tested the individual impact of including of age, YPI, AIS, BMI, MAP, and RPE in the prediction model and assessed the subsequent improvement to the prediction model with each addition (Table 4). While inclusion of RPE in the model resulted in an improvement that was close to significance $(p=0.06)$, none of the additional variables examined added significantly to the model. The regression coefficients of the model yielded the following equation to predict $\mathrm{VO}_{2}$ peak from end-stage $6 \mathrm{MAT} \mathrm{VO}_{2}$ :

$$
V O_{2} \text { peak }\left(m L \bullet \mathrm{kg}^{-1} \bullet \mathrm{min}^{-1}\right)=1.501 \times 6 M A T V O_{2}\left(\mathrm{~mL} \bullet \mathrm{kg}^{-1} \bullet \mathrm{min}^{-1}\right)-0.940
$$


SEE for the validation group was $3.68 \mathrm{~mL} \cdot \mathrm{kg}^{-1} \cdot \mathrm{min}^{-1}$ (paraplegia: $3.86 \mathrm{~mL} \cdot \mathrm{kg}^{-1} \cdot \mathrm{min}^{-1}$; tetraplegia: $2.41 \mathrm{~mL} \cdot \mathrm{kg}^{-1} \cdot \mathrm{min}^{-1}$ ), well below the recommended threshold of $5 \mathrm{~mL} \cdot \mathrm{kg}^{-1} \cdot \mathrm{min}^{-1}$ (Heyward 2006). Correlation between measured and predicted $\mathrm{VO}_{2}$ peak was excellent $(\mathrm{r}=0.89$ [95\% CI: 0.85-0.95], $\mathrm{p}<0.01$ ) (Figure 2). No significant difference was found between the measured $\left(17.26 \pm 7.43 \mathrm{~mL} \cdot \mathrm{kg}^{-1} \cdot \mathrm{min}^{-1}\right)$ and predicted $\left(17.25 \pm 6.73 \mathrm{~mL} \cdot \mathrm{kg}^{-1} \cdot \mathrm{min}^{-1}\right) \mathrm{VO}_{2}$ peak $(p=0.99)$ (Figure 3). The mean difference between measured and predicted $\mathrm{VO}_{2}$ peak was 0.01 $\mathrm{mL} / \mathrm{kg} / \mathrm{min}$.

\section{Cross Validation}

When cross validated with data from a sample of ten additional individuals with SCI, SEE remained acceptable at $3.62 \mathrm{~mL} \cdot \mathrm{kg}^{-1} \cdot \mathrm{min}^{-1}$ (paraplegia: $4.94 \mathrm{~mL} \cdot \mathrm{kg}^{-1} \cdot \mathrm{min}^{-1}$; tetraplegia: 1.36 $\left.\mathrm{mL} \cdot \mathrm{kg}^{-1} \cdot \mathrm{min}^{-1}\right)$, and correlation between measured and predicted $\mathrm{VO}_{2}$ peak remained high $(\mathrm{r}=0.89$ [95\% CI: 0.83-0.99], $\mathrm{p}<0.01)$. No significant differences $(0.61 \pm 3.77$ [95\% CI: $-3.31-2.08])$ were found between measured $\left(18.81 \pm 8.35 \mathrm{~mL} \cdot \mathrm{kg}^{-1} \cdot \mathrm{min}^{-1}\right)$ and predicted $\left(18.19 \pm 7.32 \mathrm{~mL} \cdot \mathrm{kg}^{-1} \cdot \mathrm{min}^{-}\right.$ $\left.{ }^{1}\right) \mathrm{VO}_{2}$ peak $(\mathrm{p}=0.62)$.

In order to justify the sample size of the cross-validation group, we assessed the amount of shrinkage (difference) between the coefficient of determination for the measured and predicted $\mathrm{VO}_{2}$ peak values for both the validation $\left(\mathrm{R}^{2}=0.82\right)$ and cross-validation $\left(\mathrm{R}^{2}=0.80\right)$ groups (Algina 2000). Shrinkage was small $(<0.025)$, confirming the model can predict $\mathrm{VO}_{2}$ peak in a small cross-validation sample.

\section{Discussion:}

The current study sought to validate the use of the 6MAT to predict $\mathrm{VO}_{2}$ peak among individuals with SCI. The prediction equation developed in the present study indicates that 
6MAT $\mathrm{VO}_{2}$ can be used to predict $\mathrm{VO}_{2}$ peak among individuals with chronic SCI. Regression analysis revealed end-stage $6 \mathrm{MAT} \mathrm{VO}_{2}$ to be an independent predictor of $\mathrm{VO}_{2}$ peak, and the prediction equation developed remained an accurate estimation of $\mathrm{VO}_{2}$ peak when cross validated with a smaller sample of data from other participants with similar characteristics. This is the first laboratory-based submaximal prediction equation for $\mathrm{VO}_{2}$ peak for use in individuals with SCI, and utilizes a common exercise modality available in most rehabilitation settings.

The sample used in the present study can be considered representative of the SCI population in Canada (Noonan et al. 2012; Pickett et al. 2006). The $\mathrm{VO}_{2}$ peak values found in the present group of participants with SCI were similar to others previously reported in the literature (Coutts et al. 1983; Janssen et al. 2002). Participants ranged from sedentary to competitive athletes. Using normative values that were developed from a sample of 146 men with SCI (Janssen et al. 2002), the fitness levels of the participants in the present study were classified as: 6 poor, 13 fair, 16 average, 11 good, and 6 excellent.

All participants were able to complete the 6MAT at individually selected submaximal power outputs. Several factors support the use of the 6MAT as a feasible submaximal test in the SCI population: (1) Participants exercised at an average of $73 \%$ of their $\mathrm{VO}_{2}$ peak and $59 \%$ of their age predicted maximum heart rate during the 6MAT, implying the test involved aerobic exercise. (2) The correlation between $\mathrm{VO}_{2}$ peak and 6MAT $\mathrm{VO}_{2}$ was excellent $(\mathrm{r}=0.91$ [95\% CI: 0.85 0.95]; $\mathrm{p}<0.01$ ), indicating individuals with a high $6 \mathrm{MAT} \mathrm{VO}_{2}$ also had a high $\mathrm{VO}_{2}$ peak. (3) Individual power output selection was reasonably accurate at eliciting 60-70\% of age-predicted maximal heart rate among individuals with low paraplegia, and 2-5 score on the Borg CR10 RPE scale among individuals with high paraplegia or tetraplegia. Sixty-two percent of individuals with low paraplegia and $82 \%$ of individuals with high paraplegia or tetraplegia had their power 
output set appropriately on the first attempt. These heart rate and RPE ranges are guidelines for clinical use (Hol et al. 2007), and therefore it is not mandatory that they be met in every case for the prediction equation to be accurate. However, future studies should attempt to improve the utility of the test by identifying other factors (i.e. upper limb motor scores) that may impact end stage 6MAT heart rate or RPE so that all individuals reach appropriate physiological/subjective targets.

Regression analysis revealed end-stage $6 \mathrm{MAT} \mathrm{VO}_{2}$ to be an independent variable in predicting $\mathrm{VO}_{2}$ peak. The accuracy of the generalized regression equation, as indicated by the SEE, was as good or better than that of most other methods for estimating $\mathrm{VO}_{2}$ peak, even in the able-bodied population (Baumgartner et al. 1991). The cross-validation group was not different from the validation group in any exercise outcome, had good SEE, and excellent correlation between measured and predicted $\mathrm{VO}_{2}$ peak; these findings confirm the validity of our prediction equation.

There was a trend towards significance when adding RPE into the prediction equation $(p=0.06)$, and regression analysis revealed RPE to be an independent variable in predicting $\mathrm{VO}_{2}$ peak $(\mathrm{p}<0.01)$, however it only explained $23 \%$ of the variance. Although these findings indicate RPE may be a predictor variable for $\mathrm{VO}_{2}$ peak in the SCI population, previous studies have included only those variables explaining $>80 \%$ of the variance (Kline et al. 1987; Weller et al. 1993). $\mathrm{VO}_{2}$ peak prediction equations based on RPE have been proposed on the basis of a linear relationship between $\mathrm{RPE}$ and $\mathrm{VO}_{2}$ during arm cranking (Borg et al. 1987; Eston et al. 1986). However these studies found better prediction accuracy when using higher perceptual ranges (i.e. closer to peak effort), and did not recommend using $\mathrm{RPE}$ for $\mathrm{VO}_{2}$ peak prediction in non-athletes (Al-Rahamneh et al. 2011; Goosey-Tolfrey et al. 2014). 
Field tests have previously been developed to predict $\mathrm{VO}_{2}$ peak among individuals with SCI (Cowan et al. 2012; Goosey-Tolfrey et al. 2008; Poulain et al. 1999; Vanderthommen et al. 2002; Vinet et al. 1996; Vinet et al. 2002), however these tests were designed to bring the individuals to maximal effort. The development of a submaximal exercise test to predict $\mathrm{VO}_{2}$ peak reduces the risk of adverse autonomic responses, upper body injuries, peripheral arm fatigue, and abnormal physiological responses (e.g. altered chronotropy) to high intensity exercise. Although the present study provides a useful prediction equation for $\mathrm{VO}_{2}$ peak from submaximal exercise, it still requires equipment and trained personnel to administer the test (i.e. metabolic cart). A prediction equation involving submaximal heart rate would be ideal for widespread use in a clinical population. However, the sympathetic nervous system influence on heart rate is often blunted following an injury $>\mathrm{T} 6$, resulting in a parasympathetic-dominant nervous system and a diminished cardiovascular response to exercise (Brown et al. 2008; Claydon et al. 2006). Although recent findings demonstrate that Paralympic athletes with tetraplegia are able to elevate their heart rate close to their age-predicted maximum (Currie et al. 2015), these individuals had preserved sympathetic function. The diverse autonomic impairment among individuals with SCI makes it difficult to rely on heart rate responses to exercise as a predictor for fitness or health. Previous work resulted in prediction equations for $\mathrm{VO}_{2}$ peak based on submaximal heart rate, but have only included individuals with paraplegia who have an intact sympathetic nervous system (Kofsky et al. 1983). Although a good correlation was observed between peak and submaximal heart rate in the present study $(\mathrm{r}=0.80)$, heart rate was not found to be an independent predictor of $\mathrm{VO}_{2}$ peak. Seventy-four percent of the present sample had high paraplegia or tetraplegia and therefore decreased muscle innervation in the trunk and upper extremities, and likely sympathetic nervous system impairment. These physiological differences likely resulted in lower 
$\mathrm{VO}_{2}$ peak, power output, ventilation, and heart rate in comparison to the participants with low paraplegia. A larger, more evenly distributed sample would be able to stratify individuals based on injury level. It would be interesting to further explore whether sympathetic impairment has a negative relationship with cardiovascular fitness. Investigating heart rate recovery or heart rate variability are possible avenues to clinically assess sympathetic function in the SCI population. Future work should assess autonomic function to determine whether it has any predictive capacity for $\mathrm{VO}_{2}$ peak among individuals with SCI.

\section{Summary}

We have developed and cross-validated a generalized prediction equation for estimating $\mathrm{VO}_{2}$ peak from end-stage $6 \mathrm{MAT} \mathrm{VO}_{2}$ in a sample of individuals with SCI heterogeneous in injury characteristics and demographics. The 6MAT can be implemented in a clinical setting using common exercise equipment among people of all fitness levels, and should be used as a clinical tool for assessing aerobic capacity when peak testing is not feasible.

\section{Acknowledgements}

This work was sponsored by Natural Sciences and Engineering Research Council (RGPIN 238819-13), Ontario Neurotrauma Foundation (2011-ONF-RHI-MT-888), and Ontario Graduate Scholarship (OGS).

No conflict of interest in accordance with journal policy. 


\section{References:}

ACSM 2013. ACSM's Guidelines for Exercise Testing and Prescription: Wolters Kluwer.

Al-Rahamneh, H.Q. and Eston, R.G. 2011. The validity of predicting peak oxygen uptake from a perceptually guided graded exercise test during arm exercise in paraplegic individuals. Spinal cord. 49(3): 430-434.

Algina, J. 2000. Cross-Validation Sample Sizes. Applied Psychological Measurement. 24(2): 173-179.

Aspenes, S.T., Nilsen, T.I., Skaug, E.A., Bertheussen, G.F., Ellingsen, O., Vatten, L., and Wisloff, U. 2011. Peak oxygen uptake and cardiovascular risk factors in 4631 healthy women and men. Medicine and science in sports and exercise. 43(8): 1465-1473.

Baumgartner, T.A. and Jackson, A.S. 1991. Measurement for Evaluation in Physical Education and Exercise Science. Dubuque, IA: Wm. C. Brown.

Borg, G., Hassmen, P., and Lagerstrom, M. 1987. Perceived exertion related to heart rate and blood lactate during arm and leg exercise. European journal of applied physiology and occupational physiology. 56(6): 679-685.

Brown, R. and Macefield, V.G. 2008. Assessing the capacity of the sympathetic nervous system to respond to a cardiovascular challenge in human spinal cord injury. Spinal Cord. 46(10): 666-672.

Claydon, V.E. and Krassioukov, A.V. 2006. Orthostatic hypotension and autonomic pathways after spinal cord injury. J Neurotrauma. 23(12): 1713-1725.

Coutts, K.D., Rhodes, E.C., and McKenzie, D.C. 1983. Maximal exercise responses of tetraplegics and paraplegics. Journal of applied physiology: respiratory, environmental and exercise physiology. 55(2): 479-482.

Cowan, R.E. and Nash, M.S. 2010. Cardiovascular disease, SCI and exercise: unique risks and focused countermeasures. Disabil Rehabil. 32(26): 2228-2236.

Cowan, R.E., Callahan, M.K., and Nash, M.S. 2012. The 6-min push test is reliable and predicts low fitness in spinal cord injury. Medicine and science in sports and exercise. 44(10): 1993-2000.

Currie, K.D., West, C.R., Hubli, M., Gee, C.M., and Krassioukov, A.V. 2015. Peak heart rates and sympathetic function in tetraplegic nonathletes and athletes. Medicine and science in sports and exercise. 47(6): 1259-1264.

Dallmeijer, A.J. and van der Woude, L.H. 2001. Health related functional status in men with spinal cord injury: relationship with lesion level and endurance capacity. Spinal cord. 39(11): 577-583.

de Groot, S., Post, M.W., Snoek, G.J., Schuitemaker, M., and van der Woude, L.H. 2013. Longitudinal association between lifestyle and coronary heart disease risk factors among individuals with spinal cord injury. Spinal cord. 51(4): 314-318.

Eston, R.G. and Brodie, D.A. 1986. Responses to arm and leg ergometry. British journal of sports medicine. 20(1): 4-6.

Faulkner, J., Parfitt, G., and Eston, R. 2007. Prediction of maximal oxygen uptake from the ratings of perceived exertion and heart rate during a perceptually-regulated sub-maximal exercise test in active and sedentary participants. European journal of applied physiology. 101(3): 397-407. 
Franklin, B.A., Swantek, K.I., Grais, S.L., Johnstone, K.S., Gordon, S., and Timmis, G.C. 1990. Field test estimation of maximal oxygen consumption in wheelchair users. Archives of physical medicine and rehabilitation. 71(8): 574-578.

Goosey-Tolfrey, V.L. 2006. BASES Physiological Testing Guidelines: The Disabled Athlete. In Sport and Exericse Physiology. Edited by Taylor \& Francis Group, pp. 1-2.

Goosey-Tolfrey, V.L. and Tolfrey, K. 2008. The multi-stage fitness test as a predictor of endurance fitness in wheelchair athletes. Journal of sports sciences. 26(5): 511-517.

Goosey-Tolfrey, V.L., Paulson, T.A., Tolfrey, K., and Eston, R.G. 2014. Prediction of peak oxygen uptake from differentiated ratings of perceived exertion during wheelchair propulsion in trained wheelchair sportspersons. European journal of applied physiology. 114(6): 1251-1258.

Heyward, V.H. 2006. Advanced Fitness Assessment and Exercise Prescription: Human Kinetics.

Hjeltnes, N. and Jansen, T. 1990. Physical endurance capacity, functional status and medical complications in spinal cord injured subjects with long-standing lesions. Paraplegia. 28(7): 428-432.

Hoffman, M.D. 1986. Cardiorespiratory fitness and training in quadriplegics and paraplegics. Sports medicine. 3(5): 312-330.

Hol, A.T., Eng, J.J., Miller, W.C., Sproule, S., and Krassioukov, A.V. 2007. Reliability and validity of the six-minute arm test for the evaluation of cardiovascular fitness in people with spinal cord injury. Archives of physical medicine and rehabilitation. 88(4): 489-495.

Janssen, T.W., Dallmeijer, A.J., Veeger, D.J., and van der Woude, L.H. 2002. Normative values and determinants of physical capacity in individuals with spinal cord injury. J Rehabil Res Dev. 39(1): 29-39.

Kline, G.M., Porcari, J.P., Hintermeister, R., Freedson, P.S., Ward, A., McCarron, R.F., Ross, J., and Rippe, J.M. 1987. Estimation of VO2max from a one-mile track walk, gender, age, and body weight. Medicine and science in sports and exercise. 19(3): 253-259.

Kofsky, P.R., Davis, G.M., Shephard, R.J., Jackson, R.W., and Keene, G.C. 1983. Field testing: assessment of physical fitness of disabled adults. European journal of applied physiology and occupational physiology. 51(1): 109-120.

Kohl, H.W., 3rd. 2001. Physical activity and cardiovascular disease: evidence for a dose response. Med Sci Sports Exerc. 33(6 Suppl): S472-483; discussion S493-474.

Lewis, J.E., Nash, M.S., Hamm, L.F., Martins, S.C., and Groah, S.L. 2007. The relationship between perceived exertion and physiologic indicators of stress during graded arm exercise in persons with spinal cord injuries. Archives of physical medicine and rehabilitation. 88(9): 1205-1211.

Myers, J., Lee, M., and Kiratli, J. 2007. Cardiovascular disease in spinal cord injury: an overview of prevalence, risk, evaluation, and management. Am J Phys Med Rehabil. 86(2): 142152.

Noonan, V.K., Fingas, M., Farry, A., Baxter, D., Singh, A., Fehlings, M.G., and Dvorak, M.F. 2012. Incidence and prevalence of spinal cord injury in Canada: a national perspective. Neuroepidemiology. 38(4): 219-226.

Pickett, G.E., Campos-Benitez, M., Keller, J.L., and Duggal, N. 2006. Epidemiology of traumatic spinal cord injury in Canada. Spine. 31(7): 799-805.

Poulain, M., Vinet, A., Bernard, P.L., and Varray, A. 1999. Reproducibility of the Adapted Leger and Boucher Test for wheelchair-dependent athletes. Spinal cord. 37(2): 129-135. 
van Koppenhagen, C.F., Post, M., de Groot, S., van Leeuwen, C., van Asbeck, F., StolwijkSwuste, J., van der Woude, L., and Lindeman, E. 2014. Longitudinal relationship between wheelchair exercise capacity and life satisfaction in patients with spinal cord injury: A cohort study in the Netherlands. The journal of spinal cord medicine. 37(3): 328-337.

Vanderthommen, M., Francaux, M., Colinet, C., Lehance, C., Lhermerout, C., Crielaard, J.M., and Theisen, D. 2002. A multistage field test of wheelchair users for evaluation of fitness and prediction of peak oxygen consumption. Journal of rehabilitation research and development. 39(6): 685-692.

Vinet, A., Bernard, P.L., Poulain, M., Varray, A., Le Gallais, D., and Micallef, J.P. 1996. Validation of an incremental field test for the direct assessment of peak oxygen uptake in wheelchair-dependent athletes. Spinal cord. 34(5): 288-293.

Vinet, A., Le Gallais, D., Bouges, S., Bernard, P.L., Poulain, M., Varray, A., and Micallef, J.P. 2002. Prediction of VO(2peak) in wheelchair-dependent athletes from the adapted Leger and Boucher test. Spinal cord. 40(10): 507-512.

Weller, I.M., Thomas, S.G., Corey, P.N., and Cox, M.H. 1993. Prediction of maximal oxygen uptake from a modified Canadian aerobic fitness test. Canadian journal of applied physiology $=$ Revue canadienne de physiologie appliquee. 18(2): 175-188. 


\section{Tables:}

Table 1: Participant characteristics.

\begin{tabular}{|c|c|c|c|c|}
\hline & \multicolumn{3}{|c|}{ Validation Sample } & \multirow{2}{*}{$\begin{array}{c}\text { Cross-Validation Sample } \\
\text { SCI }(n=10)\end{array}$} \\
\hline Parameter & $\operatorname{SCI}(n=52)$ & Tetra $(n=31)$ & Para $(n=21)$ & \\
\hline $\operatorname{Sex}(\mathrm{M} / \mathrm{F})$ & $44 / 8$ & $26 / 5$ & $18 / 3$ & $10 / 0$ \\
\hline Age, years & $39 \pm 10$ & $40 \pm 10$ & $36 \pm 10$ & $39 \pm 13$ \\
\hline & $38 \mathrm{~A}-\mathrm{B}$ & $21 \mathrm{~A}-\mathrm{B}$ & $17 \mathrm{~A}-\mathrm{B}$ & $6 \mathrm{~A}-\mathrm{B}$ \\
\hline AIS & $14 \mathrm{C}-\mathrm{D}$ & $10 \mathrm{C}-\mathrm{D}$ & $4 \mathrm{C}-\mathrm{D}$ & $4 \mathrm{C}-\mathrm{D}$ \\
\hline NLI & C1-L2 & $\mathrm{C} 1-\mathrm{C} 7$ & T1-L2 & C3-L3 \\
\hline YPI & $13 \pm 10$ & $15 \pm 10$ & $10 \pm 10$ & $9 \pm 9$ \\
\hline Mass, $\mathrm{kg}$ & $79.7 \pm 16.8$ & $84.6 \pm 16.7$ & $72.4 \pm 14.4 \dagger$ & $78.8 \pm 16.4$ \\
\hline Height, $\mathrm{m}$ & $1.76 \pm 0.10$ & $1.79 \pm 0.07$ & $1.71 \pm 0.11 \dagger$ & $1.77 \pm 0.06$ \\
\hline BMI, $\mathrm{kg} / \mathrm{m}^{2}$ & $25.7 \pm 4.8$ & $26.4 \pm 5.0$ & $24.7 \pm 4.4$ & $25.2 \pm 4.9$ \\
\hline $\mathrm{WC}, \mathrm{cm}$ & $95.3 \pm 13.9$ & $100.9 \pm 14.1$ & $86.8 \pm 8.4^{*}$ & $91.7 \pm 15.6$ \\
\hline $\mathrm{HR}, \mathrm{bmp}$ & $71 \pm 13$ & $68 \pm 11$ & $76 \pm 15^{*}$ & $72 \pm 9$ \\
\hline $\mathrm{SBP}, \mathrm{mmHg}$ & $109 \pm 17$ & $101 \pm 14$ & $121 \pm 13 \dagger$ & $113 \pm 19$ \\
\hline $\mathrm{DBP}, \mathrm{mmHg}$ & $68 \pm 12$ & $63 \pm 9$ & $76 \pm 10 \dagger$ & $70 \pm 11$ \\
\hline MAP, $\mathrm{mmHg}$ & $82 \pm 13$ & $75 \pm 10$ & $91 \pm 10 \dagger$ & $85 \pm 13$ \\
\hline
\end{tabular}

Values are mean \pm SD. SCI $=$ spinal cord injury; AIS = American Spinal Injury Association Impairment Scale; NLI = neurological level of injury; YPI = years post injury; BMI = body mass index; $\mathrm{WC}=$ waist circumference; $\mathrm{SBP}=$ systolic blood pressure; $\mathrm{DBP}=$ diastolic blood pressure; $\mathrm{MAP}=$ mean arterial pressure. ${ }^{*}$ p-value $<0.05$ tetraplegic vs. paraplegic in validation sample; $\dagger$ p-value $<0.01$ tetraplegic vs. paraplegic in validation sample. No significant differences between validation and cross-validation samples. 
Table 2: Physiologic Values during the $\mathrm{VO}_{2}$ peak test.

\begin{tabular}{lcccc}
\hline & \multicolumn{2}{c}{ Validation Sample $(\mathbf{n}=\mathbf{5 2})$} & \multicolumn{2}{c}{ Cross-Validation Sample (n=10) } \\
\hline Variable & Mean \pm SD & Range & Mean \pm SD & Range \\
\hline Peak PO, W & $66.0 \pm 36.7$ & $23-165$ & $73.5 \pm 43.5$ & $10-153$ \\
Peak $\mathrm{E}_{\mathrm{E}}, \mathrm{L} / \mathrm{min}$ & $46.2 \pm 21.0$ & $16.8-114.2$ & $50.8 \pm 26.7$ & $20.1-113.1$ \\
$\mathrm{VO}_{2}$ peak, $\mathrm{mL} / \mathrm{kg} / \mathrm{min}$ & $17.3 \pm 7.4$ & $5.2-38.1$ & $18.8 \pm 8.5$ & $7.1-37.5$ \\
$\mathrm{VO}_{2}$ peak, L/min & $1.31 \pm 0.48$ & $0.50-2.69$ & $1.49 \pm 0.66$ & $0.42-2.81$ \\
Peak RER & $1.05 \pm 0.13$ & $0.76-1.34$ & $1.12 \pm 0.20$ & $0.76-1.53$ \\
Peak heart rate, bpm & $133 \pm 29$ & $76-197$ & $140 \pm 29$ & $101-182$ \\
Percentage heart rate max* & $73.1 \pm 14.5$ & $44.2-105.6$ & $78.0 \pm 17.5$ & $56.3-101.9$ \\
Duration of Test, s & $510 \pm 132$ & $210-790$ & $570 \pm 200$ & $270-915$ \\
Peak RPE & $7.6 \pm 2.2$ & $3-10$ & $7.9 \pm 1.9$ & $4-10$ \\
\hline
\end{tabular}

$\mathrm{PO}=$ power output; $\mathrm{V}_{\mathrm{E}}=$ ventilation; $\mathrm{VO}_{2}$ peak = peak oxygen consumption; RER = respiratory exchange ratio.

*Based on 220-age prediction equation. No significant differences between validation and cross-validation samples. 
Table 3: Steady-state physiologic values during the 6MAT.

\begin{tabular}{lcccc}
\hline & \multicolumn{2}{c}{ Validation Sample $(\mathbf{n}=\mathbf{5 2})$} & \multicolumn{2}{c}{ Cross-Validation Sample (n=10) } \\
\hline Variable & Mean \pm SD & Range & Mean \pm SD & Range \\
\hline 6MAT PO, W & $30.1 \pm 17.0$ & $10-60$ & $36.6 \pm 20.5$ & $5-60$ \\
$\mathrm{~V}_{\mathrm{E}}, \mathrm{L} / \mathrm{min}$ & $26.9 \pm 7.5$ & $14.6-48.1$ & $28.4 \pm 11.9$ & $14.2-57.2$ \\
$\mathrm{VO}_{2}, \mathrm{~mL} / \mathrm{kg} / \mathrm{min}$ & $12.1 \pm 4.5$ & $3.9-22.9$ & $12.7 \pm 4.9$ & $3.7-18.9$ \\
$\mathrm{VO}_{2}, \mathrm{~L} / \mathrm{min}$ & $0.92 \pm 0.28$ & $0.38-1.61$ & $1.02 \pm 0.43$ & $0.21-1.69$ \\
Percentage $\mathrm{VO}_{2}$ peak & $72.6 \pm 13.4$ & $35.3-98.7$ & $68.4 \pm 11.4$ & $50.5-83.5$ \\
$\mathrm{RER}$ & $0.94 \pm 0.13$ & $0.73-1.59$ & $0.99 \pm 0.17$ & $0.82-1.35$ \\
Heart rate, bpm & $107 \pm 21$ & $61-157$ & $109 \pm 23$ & $61-93$ \\
Percentage heart rate max* & $58.9 \pm 10.6$ & $35.7-86.3$ & $60.5 \pm 11.9$ & $43.8-84.1$ \\
$\mathrm{RPE}$ & $4.1 \pm 1.8$ & $1-10$ & $3.8 \pm 0.8$ & $3-5$ \\
\hline PO $=$ power output; $\mathrm{V}_{\mathrm{E}}=$ ventilation; VO $\mathrm{V}_{2}$ peak $=$ peak oxygen consumption; RER = respiratory exchange ratio. \\
*Based on 220-age prediction equation. No significant differences between validation and cross-validation samples.
\end{tabular}


Table 4: Block entry multiple regression analyses for prediction variables in participants with SCI $(\mathbf{n}=52)$.

\begin{tabular}{|c|c|c|c|}
\hline Predictor Variable & B [95\% CI] & $\mathbf{t}$ & p-value \\
\hline \multicolumn{4}{|l|}{ Model 1: $\mathrm{F}(1,50)=232.32, \mathrm{p}<0.01, \mathrm{r}^{2}=82 \%$} \\
\hline $6 \mathrm{MAT} \mathrm{VO}_{2}$ & $1.50[1.30-1.70]$ & 15.24 & $<0.01$ \\
\hline \multicolumn{4}{|l|}{ Model 2: $\mathrm{F}(2,49)=116.27, \mathrm{p}<0.01, \mathrm{r}^{2}=83 \%$} \\
\hline $6 \mathrm{MAT} \mathrm{VO}_{2}$ & $1.47[1.27-1.68]$ & 14.24 & $<0.01$ \\
\hline Age & $-0.04[-0.14-0.005]$ & -0.93 & 0.36 \\
\hline \multicolumn{4}{|l|}{ Model 3: $\mathrm{F}(2,48)=120.09, \mathrm{p}<0.01, \mathrm{r}^{2}=83 \%$} \\
\hline $6 \mathrm{MAT} \mathrm{VO}_{2}$ & $1.47[1.27-1.67]$ & 14.67 & $<0.01$ \\
\hline YPI & $-0.08[-0.17-0.01]$ & -1.84 & 0.07 \\
\hline \multicolumn{4}{|l|}{ Model 4: $\mathrm{F}(2,49)=114.03, \mathrm{p}<0.01, \mathrm{r}^{2}=82 \%$} \\
\hline $6 \mathrm{MAT} \mathrm{VO}_{2}$ & $1.51[1.30-1.72]$ & 14.62 & $<0.01$ \\
\hline AIS & $0.13[-0.85-1.10]$ & 0.26 & 0.80 \\
\hline \multicolumn{4}{|l|}{ Model 5: $\mathrm{F}(2,49)=113.84, \mathrm{p}<0.01, \mathrm{r}^{2}=82 \%$} \\
\hline $6 \mathrm{MAT} \mathrm{VO}_{2}$ & $1.50[1.26-1.73]$ & 12.78 & $<0.01$ \\
\hline BMI & $-0.01[-0.23-0.22]$ & -0.05 & 0.96 \\
\hline \multicolumn{4}{|l|}{ Model 6: $F(2,48)=116.34, p<0.01, r^{2}=83 \%$} \\
\hline $6 \mathrm{MAT} \mathrm{VO}_{2}$ & $1.46[1.25-1.67]$ & 13.95 & $<0.01$ \\
\hline MAP & $0.05[-0.02-0.13]$ & 1.43 & 0.16 \\
\hline \multicolumn{4}{|l|}{ Model 7: $\mathrm{F}(2,47)=114.90, \mathrm{p}<0.01, \mathrm{r}^{2}=83 \%$} \\
\hline $6 \mathrm{MAT} \mathrm{VO}_{2}$ & $1.44[1.22-1.66]$ & 13.08 & $<0.01$ \\
\hline CR10 & $0.50[-0.02-1.03]$ & 1.93 & 0.06 \\
\hline
\end{tabular}

$\mathrm{B}=$ unstandardized beta; $\mathrm{VO}_{2}=$ oxygen uptake; $\mathrm{YPI}=$ years post injury; $\mathrm{AIS}=$ American Spinal Injury Association Impairment Scale; $\mathrm{BMI}=$ body mass index; $\mathrm{MAP}=$ mean arterial pressure; $\mathrm{CR} 10=$ rate of perceived exertion on Borg 0-10 scale. 


\section{Figure Captions:}

Figure 1: Distribution of Participant Lesion Levels (Validation Sample $\mathbf{n = 5 3}$ ).

Figure 2: Scatterplot comparing measured and predicted $\mathrm{VO}_{2}$ peak.

Figure 3: Bland Altman (95\% limits of agreement) of difference in measured and predicted $\mathrm{VO}_{2}$ peak versus mean of measured and predicted $\mathrm{VO}_{2}$ peak. 


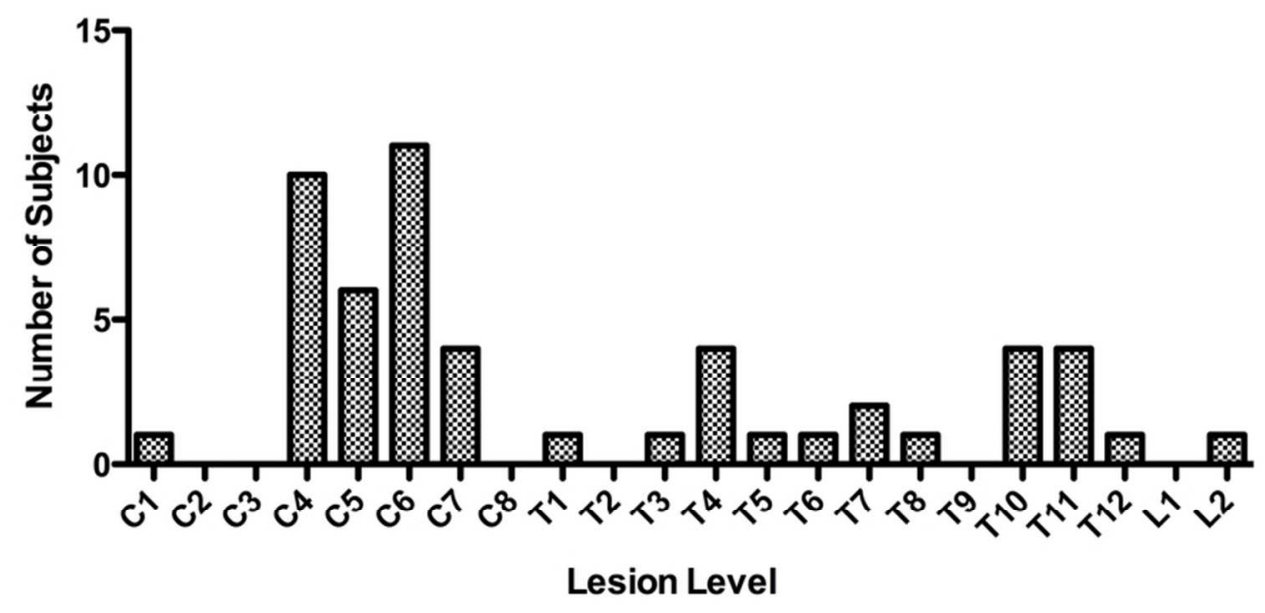

Figure 1: Distribution of Participant Lesion Levels (Validation Sample $n=53$ ). $77 \times 39 \mathrm{~mm}(300 \times 300 \mathrm{DPI})$ 


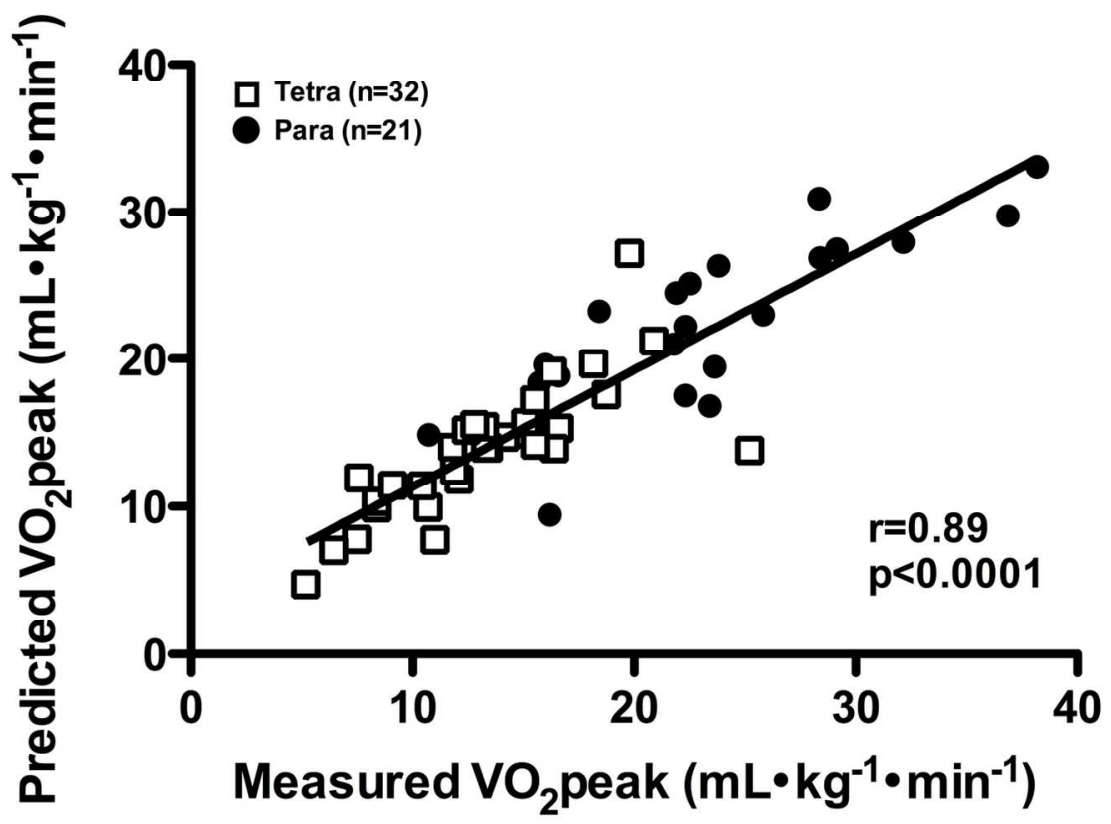

Figure 2: Scatterplot comparing measured and predicted VO2peak. $143 \times 103 \mathrm{~mm}(300 \times 300$ DPI $)$ 


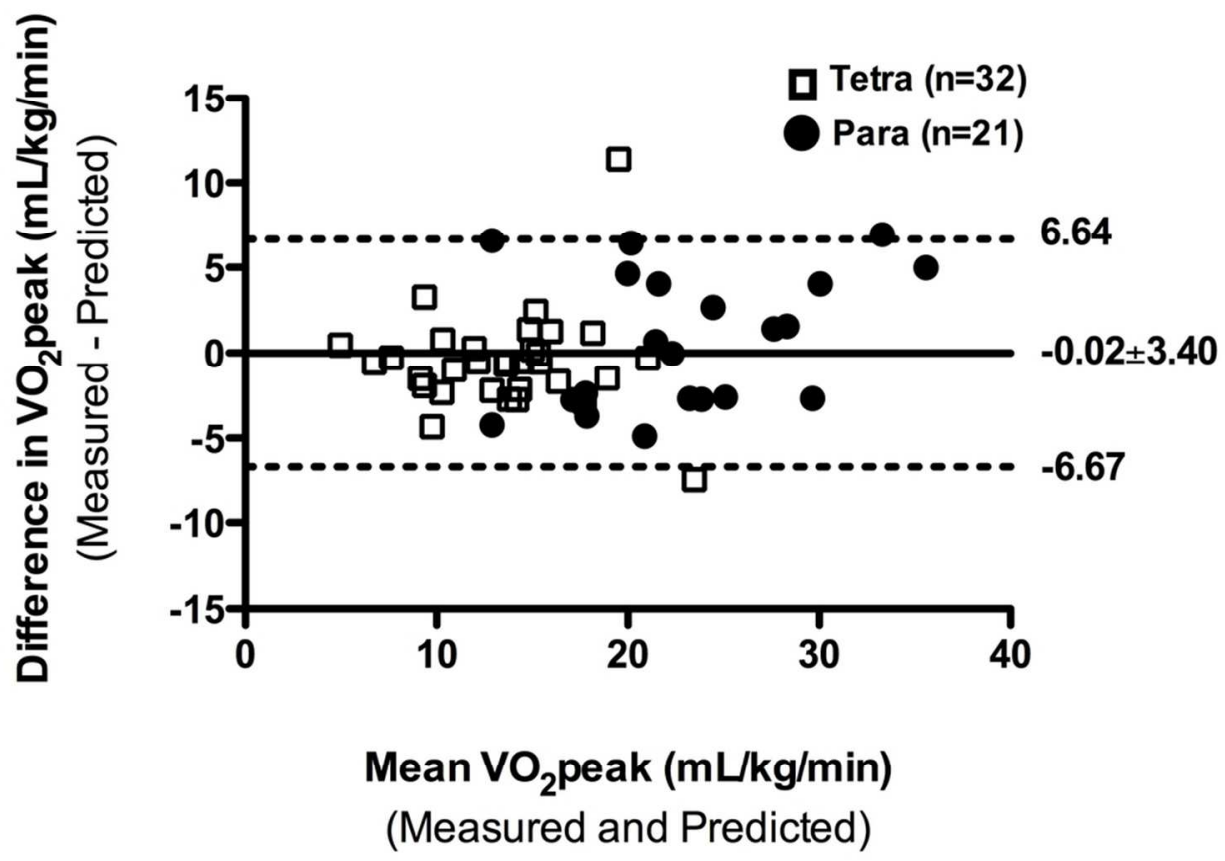

Figure 3: Bland Altman (95\% limits of agreement) of difference in measured and predicted VO2peak versus mean of measured and predicted VO2peak. $92 \times 66 \mathrm{~mm}(300 \times 300 \mathrm{DPI})$ 